Pacific Journal of Mathematics

CRITERIA FOR BANACH SPACES

EarL Valentine and Stanley G. Wayment 


\section{CRITERIA FOR BANACH SPACES}

\section{J. E. VALENTine AND S. G. WAYMENT}

It is well known in euclidean geometry that the quadrilateral obtained from an arbitrary quadrilateral by joining its midpoints is a parallelogram. The purpose of this paper is to show that a complete metric space with a unique metric line joining any pair of its distinct points is a Banach space if and only if it has the above mentioned property.

Let $p, q, r$, and $s$ be distinct points in a Banach space such that no three are linear let $m_{1}, m_{2}, m_{3}$, and $m_{4}$ be the midpoints of the algebraic segments joining $p$ and $q, q$ and $r, r$ and $s$, and $s$ and $p$, respectively. It is well known that $m_{3}-m_{2}=m_{4}-m_{1}$ and $m_{2}-m_{1}=$ $m_{3}-m_{4}$. In Euclidean space one usually refers to this result by saying that the midpoints $m_{1}, m_{2}, m_{3}, m_{4}$ form a parallelogram. If the Banach space does not have unique segments joining pairs of distinct points, then the restriction that the $\left\{m_{i}\right\}$ be midpoints of algebraic segments is easily seen to be necessary. We shall say that the metric space $M$ satisfies the quadrilateral midpoint postulate provided that if $p, q, r, s$ are points of $M$ such that no three are linear and if $m_{1}$, $m_{2}, m_{3}, m_{4}$ are the respective midpoints, then $m_{1} m_{2}=m_{3} m_{4}$ and $m_{2} m_{3}=$ $m_{1} m_{4}$. Hereafter we shall assume that $M$ is a complete metric space with a unique metric line joining any pair of its distinct points and show that the Quadrilateral Midpoint Postulate characterizes the class of Banach spaces among such metric spaces.

The technique will be to show that a complete metric space with a unique metric line joining any pair of its distinct points satisfies the Quadrilateral Midpoint Postulate if and only if it satisfies the Young Postulate which may be stated as follows.

The Young Postulate. If $p, q, r$ are points of a metric space $M$ and $q^{\prime}$ and $r^{\prime}$ are the midpoints of $p$ and $q$, and $p$ and $r$, respectively, then $q^{\prime} r^{\prime}=q r / 2$.

The result will then follow, for Andalafte and Blumenthal [1] have shown that a complete metric space with a unique metric line joining any pair of its distinct points is a Banach space if and only if it satisfies the Young Postulate.

That the Young Postulate implies the Quadrilateral Midpoint Postulate is almost immediate. For if a complete metric space with a metric line joining any pair of its distinct points satisfies the Young Postulate, then it is a Banach space and consequently satisfies the Quadrilateral Midpoint Postulate. 
Suppose $M$ satisfies the Quadrilateral Midpoint Postulate and $p$, $q, r$, are non-linear points of $M$ with $m_{1}, m_{2}$ the midpoints of $p$ and $q, q$ and $r$, respectively.

LEMMA 1. There exists a number $k$, depending only on $p$ and $r$, such that if $q, m_{1}, m_{2}$ are as above, then $m_{1} m_{2}=k p r$.

Proof. Let $s$ be a point such that no three of $p, q, r, s$ are collinear, and let $m_{3}, m_{4}$ be the midpoints of the segments joining $r$ and $s, s$ and $p$, respectively. Let $k=m_{3} m_{4} / p r$. Then since $M$ satisfies the quadrilateral midpoint property, $m_{1} m_{2}=m_{3} m_{4}=k p r$. We see immediately that $k$ does not depend on $q$.

\section{Lemma 2. The $k$ in Lemma 1 is $1 / 2$.}

Proof. Let $\left\{x_{i}\right\}$ be a sequence of points tending to $x$ on the segment between $p$ and $r$ with $p \neq x \neq r$ and such that for each $i$ we have $p, x_{i}, r$ non-collinear. Let $\left\{p_{i}\right\}$ and $\left\{r_{i}\right\}$ be the sequences such that $p_{i}$ and $r_{i}$ are the midpoints of the segments determined by $p$ and $x_{i}, r$ and $x_{i}$, respectively. Then $\lim p_{i} x_{i}=1 / 2 \lim p x_{i}=1 / 2 p x$ and similarly $\lim r_{i} x_{i}=1 / 2 r x$. This, along with the triangle inequality $p_{i} x_{i}+x_{i} r_{i} \geqq p_{i} r_{i}=k p r$, implies $k \leqq 1 / 2$. However, the inequality $p r \leqq p p_{i}+p_{i} r_{i}+r_{i} r=p p_{i}+k p r+r_{i} r$ and the aforementioned limits imply $k \geqq 1 / 2$. Hence $k$ is $1 / 2$.

THEOREM. A complete metric space with a unique line joining any two of its distinct points is a normed linear space (Banach Space) if and only if it satisfies the Quadrilateral Midpoint Postulate.

Proof. We have shown that the Quadrilateral Midpoint Postulate implies the Young Postulate; that is, if $p^{\prime}$ and $r^{\prime}$ are midpoints of $p$ and $q$, and $q$ and $r$, respectively, then $p^{\prime} r^{\prime}=(1 / 2) p r$. Thus an application of the Andalafte-Blumenthal result [1] completes the proof.

\section{REFERENCES}

1. E. Z. Andalafte and L. M. Blumenthal, Metric characterization of banach and euclidean spaces, Fund. Math., LV (1964), 23-55.

Received August 16, 1971.

Utah State University 


\section{PACIFIC JOURNAL OF MATHEMATICS}

\section{EDITORS}

\section{H. SAMElson}

Stanford University

Stanford, California 94305

C. R. Новву

University of Washington

Seattle, Washington 98105
J. DugunduI

Department of Mathematics University of Southern California

Los Angeles, California 90007

RICHARD ARENS

University of California

Los Angeles, California 90024

\section{ASSOCIATE EDITORS}
E. F. BECKENBACH
B. H. NeUmanN
F. WOLF
K. YosHIDA

\section{SUPPORTING INSTITUTIONS}

UNIVERSITY OF BRITISH COLUMBIA

UNIVERSITY OF SOUTHERN CALIFORNIA

CALIFORNIA INSTITUTE OF TECHNOLOGY

STANFORD UNIVERSITY

UNIVERSITY OF CALIFORNIA

UNIVERSITY OF TOKYO

MONTANA STATE UNIVERSITY

UNIVERSITY OF UTAH

UNIVERSITY OF NEVADA

WASHINGTON STATE UNIVERSITY

NEW MEXICO STATE UNIVERSITY

OREGON STATE UNIVERSITY

UNIVERSITY OF OREGON

OSAKA UNIVERSITY

UNIVERSITY OF WASHINGTON

* *

AMERICAN MATHEMATICAL SOCIETY

NAVAL WEAPONS CENTER 


\section{Pacific Journal of Mathematics}

\section{Vol. 43, No. $1 \quad$ March, 1972}

Alexander (Smbat) Abian, The use of mitotic ordinals in cardinal

arithmetic ....................................... 1

Helen Elizabeth. Adams, Filtrations and valuations on rings ......... 7

Benno Artmann, Geometric aspects of primary lattices .............. 15

Marilyn Breen, Determining a polytope by Radon partitions ........... 27

David S. Browder, Derived algebras in $L_{1}$ of a compact group .......... 39

Aiden A. Bruen, Unimbeddable nets of small deficiency .............. 51

Michael Howard Clapp and Raymond Frank Dickman, Unicoherent

compactifications ............................... 55

Heron S. Collins and Robert A. Fontenot, Approximate identities and the strict topology ................................... 63

R. J. Gazik, Convergence in spaces of subsets................. 81

Joan Geramita, Automorphisms on cylindrical semigroups ........... 93

Kenneth R. Goodearl, Distributing tensor product over direct product ..... 107

Julien O. Hennefeld, The non-conjugacy of certain algebras of

operators ................................... 111

C. Ward Henson, The nonstandard hulls of a uniform space ........... 115

M. Jeanette Huebener, Complementation in the lattice of regular

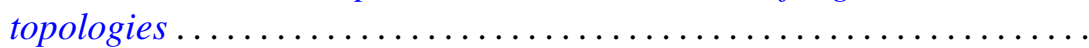

Dennis Lee Johnson, The diophantine problem $Y^{2}-X^{3}=A$ in a

polynomial ring .................................... 151

Albert Joseph Karam, Strong Lie ideals . . . . . . . . . . . . . . . . . . . . 157

Soon-Kyu Kim, On low dimensional minimal sets ............... 171

Thomas Latimer Kriete, III and Marvin Rosenblum, A Phragmén-Lindelöf

theorem with applications to $M(u, v)$ functions ..... . .

William A. Lampe, Notes on related structures of a universal algebra . . . . 189

Theodore Windle Palmer, The reducing ideal is a radical .

207

Kulumani M. Rangaswamy and N. Vanaja, Quasi projectives in abelian and module categories ................................ 221

Ghulam M. Shah, On the univalence of some analytic functions ......... 239

Joseph Earl Valentine and Stanley G. Wayment, Criteria for Banach

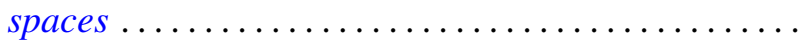

Jerry Eugene Vaughan, Linearly stratifiable spaces ............... 253

Zbigniew Zielezny, On spaces of distributions strongly regular with respect to partial differential operators ..................... 